\title{
ПРОИЗВОДНЬЕ ОТ ФАМИЛИЙ ПОЛИТИЧЕСКИХ И ОБЩЕСТВЕННЫХ ДЕЯТЕЛЕЙ КАК ПОКАЗАТЕЛИ АГОНАЛЬНОСТИ ПОЛИТИЧЕСКОГО ДИСКУРСА
}

\section{DERIVATIVES FROM THE SURNAMES OF POLITICAL AND PUBLIC ACTORS AS INDICATORS OF POLITICAL DISCOURSE AGONALITY}

\section{N. Bolgova}

Summary: The article is devoted to the description of the role of derivatives from the surnames of political and public figures (navalnyat, sorosyat, Chubaisyat, Kiselyovshchina, Solovyovshchina, Yeltsinism) in the formation of the agonality of political discourse. The purpose of this work is to consider derivatives of the names of political and public figures as markers of agonism in political discourse. The work shows that derivatives from the names of political and public figures are a means of implementing various strategies in political discourse: nominative, communicative, discursive, cognitive. It is proved that the function of agonality of the derivative is especially important, marking the discourse as oppositional (putler, Lukashism, Navalderthal). The practical significance of the work lies in the fact that the study of derivatives from surnames in the aspect of the relationship between language, culture and consciousness may be useful for preventing conflicts in the context of communicative perversion.

Keywords: political discourse, agonism, names of political and public figures.

\section{Актуальность работы}

$\Pi$ олитический дискурс выделяется среди институциональных на основе обобщённой политической деятельности. Объектом обсуждения в таком дискурсе становятся политическое событие, ситуация, политический или общественный деятель, политическая дискуссия, политическая оценка ситуации, поведения политика и т.п. Доминирующим концептом в политическом дискурсе является власть [18; 19].

Исследование дискурса вообще и политического дискурса в частности стало одним из развивающихся направлений современной лингвистики. Политический дискурс отличает яркая выраженность личностного начала, что обусловлено установкой на воздействие.

Среди исследований политического дискурса выделяются такие направления, как коммуникативно-прагматическое [6], семиотическое [17], когнитивное [16, с. 85-
Болгова Наталья Сергеевна

Аспирант, Северный (Арктический) федеральный университет имени М.В. Ломоносова, Архангельск natali609@yandex.ru

Аннотация: Статья посвящена описанию роли производных от фамилий политических и общественных деятелей (навальнята, соросята, чубайсята, киселёвщина, соловьёвщина, ельцинизм) в формировании агональности политического дискурса. Цель работы - рассмотреть производные от фамилий политических и общественных деятелей как маркеров агональности в политическом дискурсе. В работе показано, что производные от фамилий политических и общественных деятелей являются средством реализации различных стратегий в политическом дискурсе: номинативных, коммуникативных, дискурсивных, когнитивных. Доказано, что особенно важна функция агональности производного, маркирующая дискурс как оппозиционный (путлер, лукашизм, навальдерталец). Практическая значимость работы состоит в том, что исследование производных от фамилий в аспекте взаимосвязи языка, культуры и сознания может оказаться полезным для предотвращения конфликтов в условиях коммуникативной перверсии.

Ключевые слова: политический дискурс, агональность, фамилии политических и общественных деятелей.

93 и др.], сопоставительное [3 и др.], прагматическое [7], лингвоэкологическое [11] и др. Учитывая специфику политического дискурса как нацеленного на реализацию стратегии воздействия, нельзя не отметить работы, посвящённые анализу коммуникативных стратегий и тактик в современном политическом дискурсе [1; 4 и др.].

На основании исследований политического дискурса мы пришли к выводу об интеграции в нём других видов дискурса: собственно политического, медиадискурса, манипулятивного и агонального дискурсов. Если в институциональном политическом дискурсе коммуникация осуществляется в заданных рамках, то в неинституционом она выходит за пределы этих рамок. В обоих видах политического дискурса есть актуализация сферы политика. Особенно это заметно в политическом дискурсе оппозиционной прессы.

Цель работы - рассмотреть производные от фамилий политических и общественных деятелей как марке- 
ров агональности в политическом дискурсе.

Задачи исследования состоят в том, чтобы исследовать когнитивные и языковые механизмы интерпретации производных на базе фамилий политических и общественных деятелей, показать, средством реализации каких стратегий являются исследуемые лексические единицы, и каким образом это создает агональность политического дискурса.

\section{Методология и методы исследования}

Феномен производных от фамилий политических деятелей описывается в работе в русле современной научной парадигмы - когнитивно-дискурсивной. Методами исследования являются дефиниционный и компонентный анализы, концептуальный анализ фамилии и производных слов и дискурс-анализ.

Материал исследования - авторская картотека, содержащая 1200 производных, образованных на базе фамилий политических и общественных деятелей. Производные и непроизводные, но мотивированные фамилиями, номинации выделены нами методом сплошной выборки из СМИ, том числе электронных. Поскольку в работе речь идёт о современных языковых процессах, хронологические рамки исследования ограничиваются двумя последними десятилетиями (2000-2020 гг.). Средой функционирования производных от фамилий политических и общественных деятелей избраны как нейтральные, так и провластные и оппозиционные СМИ с целью повышения объективности выводов.

Как отмечают исследователи, изучение агональности в науке только начинается и она заключается в борьбе, состязательности, соперничестве, нацеленности на достижение победы. Целью агонального дискурса является установление превосходства, доминирование в отношениях, победа на выборах и т. д. [14, с.3].

\section{Результаты исследования}

В оппозиционных СМИ и комментариях политического события производные от фамилий политических деятелей часто выступают маркерами агональности (противоборства) дискурса в целом. Следует заметить, что производные от фамилий входят в речевое употребление не постепенно, а сразу в соответствии с интенцией носителя лингвокультуры. Выбор модели номинации обусловлен социокультурными и политическими особенностями развития общества, реализующего новые аффиксы и новые семантические компоненты их значений. Любое экспрессивно-оценочное средство имеет национально-культурную обусловленность. Это проявляется и в производных от фамилий. Большинство таких производных образовано на базе конвенциональных дери- вационных моделей, а в их основе лежат этнокультурно обусловленные мотивационные признаки. Например, структурообразующей основой производных навальняma, соросята, чубайсята и др. стал образ детей, духовно и интеллектуально незрелых, неопытных, нуждающихся в руководстве, покровительстве, наставничестве. В производных реализуется образная мотивация, которая по природе не может быть объективной. Референт, стоящий за производными, осмысливается как находящийся в подчинении, ведомый, не имеющий собственного мнения, не умеющий объективно оценить политическую ситуацию. Ср.: Лежу калачиком и похныкиваю» - Раскрыта схема глумления над Россией для дрессированных «навальнят» [8]. «Приватбанк», соросята и бенфилы: «Перетягивание каната упырями» [12]. Следует заметить, что в этих производных наблюдается переосмысление понятийного компонента лексического значения: навальнята - это «бездумные последователи, слепо следующие за своим кумиром, не зная даже его программы», соросята - «те, кто следует западному образу жизни и западным ценностям», чубайсята - «люди, оторванные от реальной жизни». Однако можно говорить и о факультативном характере их семантики. В других источниках эти же производные трактуются иначе. Например, «навальнята» - это школьники быдловатого характера, которые являются сторонниками Навального. У них развит стадный инстинкт. Они вспыльчивы и пугливы, не знают даже программу того, кого поддерживают. Навальнёнок не думает головой сам - за него думает Навальный и его соратники [9]. Соросята - проводники неоколонизации, критическая масса прозападников [12]. Изменению может подвергаться и сам денотат: киселёвщина - «диагноз», соловьёвщина - «стиль агрессивной пропаганды», ельцинизм - «болезнь».

Осуществление агональной интенции (функции), то есть подчеркивание противоборства идей с целью превосходства, происходит за счет использования адресантом (говорящим) производных от фамилий политических и общественных деятелей для реализации различных стратегий: номинативных, коммуникативных, дискурсивных, когнитивных. Производные от фамилий являются средством реализации названных стратегий.

По нашим наблюдениям, производные от фамилий по природе являются номинативными единицами, так как фиксируют событие, политическую ситуацию и пр. вне связи с конкретной речевой ситуацией и вне связи с позицией говорящего (например, зафиксированные в словарях производные типа брежневизм, маниловщина и под.). Адресант посредством такого производного называет то или иное явление действительности, вычленяя в нём что-то важное для себя. В этом состоит их номинативная стратегия.

Коммуникативные стратегии, нацеленные на реа- 
лизацию той или иной задачи ведения и поддержки коммуникации, реализуются тактиками языковой игры, особенно актуальной для производства на базе фамилий политических и общественных деятелей, тактикой демократизации и диалогизации речи. Адресант для привлечения внимания использует тактики экспрессивизации речи, эмоционального и интеллектуального воздействия, поскольку реализует и стратегии побуждения адресата, изменения его поведения. Исследованный материал показывает, что в оппозиционном дискурсе с этой целью используется негативная оценочность ряда таких производных.

Дискурсивные стратегии базируются на дискурсивных средствах. Это использование речевых сценариев дискредитации, навешивания ярлыков, агрессии, формирования образа врага, корреляции модели адресата и др.

Когнитивные стратегии использования производных от фамилий базируются на таких когнитивных процессах, как замена пресуппозиций, изменение направления концептуализации, формирование и расширение концептуальных сфер, моделирование ценностных установок адресата, воздействие на ментальную сферу адресата, внедрение концептуальных конструкций (например, смысловых конструктов), направленных на изменение системы ценностей адресата и т.п.

Рассмотрим производное ельцинизм. В дискурсе производное наполняется новым смыслом: «Такие вещи, как ельцинизм - концлагерь напополам с КВН-ом, казни под студенческие шуточки - не случаются с народом, если народ не постигла духовная смерть (в нашем случае, будем надеяться, клиническая). Ельцинизм мастерски вплёл в себя все низменные, порочные, гнусные, скрытые стороны человеческой природы, человеческого смрадного нутра. Ельцинизм опёрся на них всей своей грузной и разлагающейся массой. Ельцинизм оплатил горами трупов и реками слёз, невозвратными территориальными потерями, гниющими гражданскими войнами, смертью культуры, образования, науки, человеческой мечты - особняки и иностранные отели «олл инклюзив» для всех шакалов и гиен... Ельцинизм не совместим с жизнью... Он убивает. [5]. В данном дискурсе взаимодействуют несколько концептуальных сфер: политика, игра / сцена, человек, смерть, жизнь, культура, образование, наука, война, государство, животный мир и др. Когнитивными механизмами формирования смысла производного от фамилии становятся концептуальная метафора, метонимия и гипербола, доходящие до абсурда. Границы между метафорой и метонимией в дискурсе размыты. Дискурсивное значение производного ельцинизм «период правления Ельцина, при котором разрушению подверглись наука, образование, культура, экономика, социальная сфера и др., а также произошла духовная деградация народа». Мотивационная модель базирует- ся на взаимодействии следующих сфер: человек (президент Ельцин) - деятельность (президента) - результат (разрушение, деградация) - оценка (негативная). Доминирует образно-чувственная стратегия номинации установка на образы концлагеря, КВН, разлагающуюся массу, смрад, шакалов, гиен и т.п. Хотя присутствует и негативно-оценочная установка. Мотивационная структура представляет собой совокупность оценочных признаков, образов, пресуппозиций и пропозиций. Образы актуализируют негативные коннотации. Например, образ концлагеря маркирует коннотацию трагичности, а образ КВН - коннотацию комичности. В целом ельцинизм отождествляется с трагикомическим политическим режимом, доведённым до абсурда. Формируется пресуппозиция: В период правления президента Б.Н. Ельчина произошли разрушение России и деградация общества (актуализируется образ разлагающегося трупа, отождествляемого с политическим режимом президента Ельцина). Адресант осуждает этот режим, выражая своё негативное отношение к нему. Средством воздействия становятся образы.

В оппозиционных дискурсах трудно определить объективную сторону номинации. Ср.: Особенность ельцинизма в том, что он не является ни идеологией, ни социальной системой. Ельцинизм возник в обществе точно так же, как в машине возникает ржавчина, в линзе - трещина, а в чайнике - накипь. Это гнилостно-бродильный продукт разложения политической и кадровой систем, экономики, общественного ума и совести. Это сочиальная энтропия в чистом и кончентрированном виде. Стоял дом, сгнил, рухнул - полученная в итоге куча и есть ельцинизм [15]. Мотивационная структура термина состоит из оценочных образов, с которыми отождествляется понятие. Авторские дефиниции актуализируют концептуальные признаки разрушения, разложения, уничтожения. Доминирует субъективный аспект мотивационной структуры. Формируется дискурсивное значение: ельцинизм - это «прочесс разрушения политической и кадровой систем, экономики, разложения общества и последствия этого прочесса». Интересно отождествление концептуальных сфер политика, экономика, общество со сферой болезнь: Ельцинизм - это массовая эпидемия, это вирус, это страшная антисоветская зараза, способная при благоприятных условиях неожиданно вспыхнуть и заразить миллионы прежде нормальных людей в отдельно взятой стране, внушить им разрушительные мысли, парализовать властные структуры и целое государство [10]. Актуализируется пресуппозиция: ельцинизм - опасное явление, и с ним необходимо бороться. Ельцинизм объективируется и в антропоморфном образе: Словно бомжеватый и полный сил голодранеи, неожиданно дорвавшийся до власти, ельцинизм начисто отрицает всякую мораль и нравственность, бравирует своим воинственным скотством и невежеством, искушает людей неслыханной 
вседозволенностью и абсолютной безответственностью перед законом [10]. Концептуализируются такие признаки, как «отсутствие морали, нравственности», «воинственное скотство», «невежество», «вседозволенность», «абсолютная безответственность». Одна концептуальная область может использоваться для интерпретации элементов других категорий благодаря наличию аналогичных отличительных признаков субкатегориального уровня, таких как форма, размер, функция и т.д. [2, с.14]. Например, политический режим Ельцина оценивается как разрушительный через образ ржавчины (аналогия по функции).

Как видно из анализа, адресант политического дискурса намеренно выбирает средства воздействия для реализации коммуникативной цели. При этом могут нарушаться конвенциональные нормы коммуникативного кодекса. Так, в анализируемом дискурсе основная цель адресанта - скомпрометировать, понизить социальный статус президента Б. Ельцина, который в дискурсе становится адресатом-референтом: Ельцин - это охвативший весь народ морок подлой хитрости, ненасытной и глупой в своей откровенности жадности и трусливого предательства... Ельцин - это мы... [10]. Фамилия изменяет направление концептуализации в производном ельцинизм на морально-оценочное. Поэтому реализуется не традиционное значение, а дискурсивное. Мотивированное слово становится инструментом выражения модально-оценочного отношения адресанта к деятельности Б.Н. Ельцина и результатам этой деятельности. Негативная информация в дискурсе представлена тенденциозно, избыточно, а предметом обсуждения (описания) становится не само политическое событие, ситуация, политический режим, а отношение к ним адресанта.

\section{Выводы}

Анализ материала показал, что производные от фамилий фиксируют и репрезентируют структуры знания модально-оценочного компонента языкового сознания (см. об этом [13]). В таких производных языковая информация взаимодействует с экстралингвистической, причём языковая информация эксплицитна, а экстралингвистическая - имплицитна. Объём имплицитной информации в политическом дискурсе расширяется. Адресант кодирует смысл производного в соответствии со своим мировоззрением, этнокультурными традициями, ценностными установками. Основной когнитивный механизм формирования нового значения производного - концептуальная деривация. Особенно важна при этом функция агональности производного, маркирующая дискурс как оппозиционный (путлер, лукашизм, навальдерталец и др.). Производные от фамилий политических и общественных деятелей являются средством реализации различных стратегий: номинативных, коммуникативных, дискурсивных, когнитивных.

\section{ЛИТЕРАТУРА}

1. Антонова Ю.А. Коммуникативные стратегии и тактики в современном газетном дискурсе (отклики на террористический акт): автореф. дис. ... канд. филол. наук. Екатеринбург, 2007.

2. Болдырев Н.Н. Когнитивные схемы языковой интерпретации // Вопросы когнитивной лингвистики. 2016. № 4. С. 10-20.

3. Будаев Э.В., Чудинов А.П. Метафора в политическом дискурсе: монография. Екатеринбург: Уральский педагогический университет, 2006.

4. Иссерс О.С. Речевое воздействие. М.: Флинта; Наука, 2011.

5. Как Ельцин ушел с поста президента - изучаем детально. Режим доступа: https://newsu.ru/politika/ya-uhozhu-prozvuchalo-10-let-nazad.html (дата 0бращения: 29.09.2021).

6. Карамова А.А. Современный политический дискурс: автореф. дис.... д-ра. филол. наук. Уфа, 2013.

7. Кобец Е.В. Коммуникативно-прагматическая специфика политического дискурса (на материале речей А.И. Лебедя): автореф. дис. ... канд. филол. наук. Абакан, 2012.

8. Лежу калачиком и похныкиваю» - Раскрыта схема глумления над Россией для дрессированных «навальнят». 05.02.2018. Режим доступа: https://

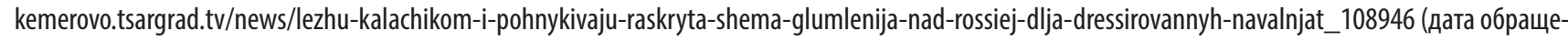
ния: 29.09.2021).

9. Навальнята. Режим доступа: http://neolurk.org/wiki (дата обращения: 29.09.2021).

10. 10сенев 0.А. Что такое ельцинизм и как с ним бороться? Режим доступа: https://pub.wikireading.ru/110823 (дата 0бращения: 29.09.2021).

11. Пекарская И.В., Шпонет Е.А. Речевая агрессия как нарушение лингвоэкологических норм в масс-медийном пространстве современного политического дискурса // Экология языка и коммуникативная практика. 2016. № 1. С. 120-140.

12. «Приватбанк», соросята и бенфилы: «Перетягивание каната упырями». 26.11.2019. Режим доступа: https://eadaily.com/ru/news/2019/11/26/privatbanksorosyata-i-benifily-peretyagivanie-kanata-upyryami (дата обращения: 29.09.2021).

13. Сидорова Т.А. Когнитивные механизмы формирования социально-политического дискурса // Когнитивные исследования языка. Вып. 30. Тамбов: ТГУ им. Г.Р. Державина. 2017. С. 628-631.

14. Соловьянова Е.В. Агональность в академическом дискурсе: автореф. дис. ... канд. филол. наук. Воронеж, 2020.

15. Сысоев, Б.А. ЕльЦинизм. Режим доступа: http://infonarod.ru/comment/9175\#comment-9175 (дата обращения: 29.09.2021). 
16. Чудинов А.П. Постулаты Уральской школы политической метафорологии // Уральский филологический вестник. Язык. Система. Личность: Лингвистика креатива. 2012. № 2. С. 85-93.

17. Шейгал Е.И. Семиотика политического дискурса. Волгоград: Перемена, 2004. 368 с.

18. Amatov A.M., Sedykh A.P., Ivanishcheva O.N., Sidorova T.A., Bolgova N.S., Zamarina E.V. Ideological American political discourse // Revista Turismo:Estudos \& Práticas. 2020. № 5. Pp. 1-9.

19. Sedykh A.P., Ivanishcheva 0.N., Sidorova T.A., Bolgova N.S., Bolgova E.V. Politician's linguistic personality as key figure of institutional discourse // Revista Inclusiones. 2020. Vol. 7. Pp. 347-358.

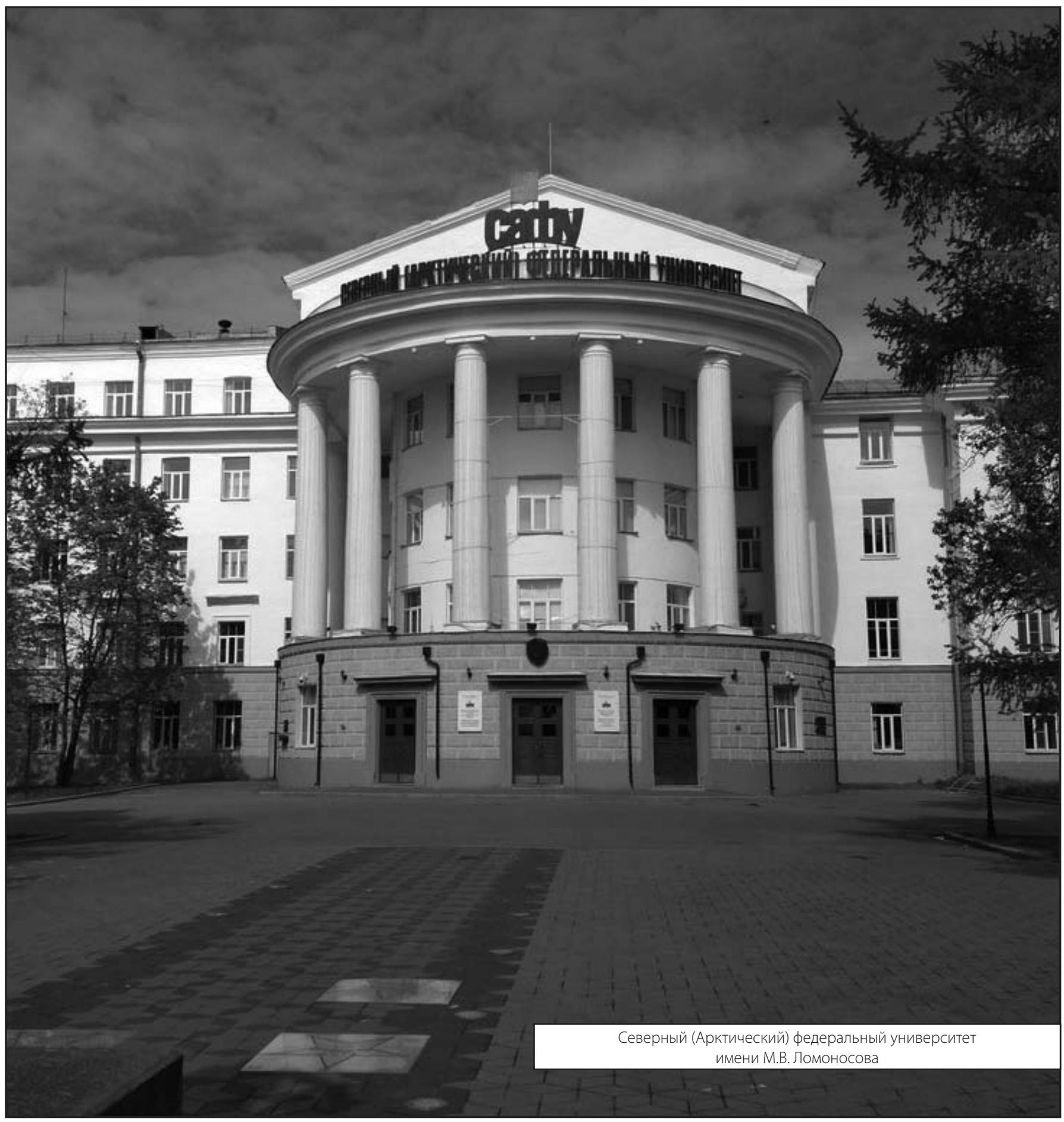

